$\gg$ epad

Vol. 2, N. 1, Abril/2018

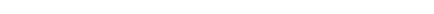




\title{
GESTÃO DE MATERIAIS NO SERVIÇO PÚBLICO: proposição de um modelo para os cemitérios de Rondonópolis - MT
}

\section{MANAGEMENT OF MATERIALS IN THE PUBLIC SERVICE: Proposition of a model for the cemeteries of Rondonópolis - MT}

Jennifer Nogueira Feitosa Silva Graduanda de Administração na Universidade Federal de Mato Grosso https://orcid.org/0000-0002-1725-0060

Carlos Sérgio Rodrigues Queiróz Graduando de Administração na Universidade Federal de Mato Grosso https://orcid.org/0000-0001-9228-3287

Adriana Paes Soares Graduanda de Administração na Universidade Federal de Mato Grosso https://orcid.org/0000-0003-2013-0489

\section{RESUMO}

Este estudo propõe um modelo de gestão de materiais pautadas no planejamento para Administração pública dos cemitérios de Rondonópolis-MT e, portanto, não deve ser interpretado como conteúdo prescritivo, pois não se trata de um manual que congrega instruções, mas em uma proposta de modelo de Gestão de Materiais e por tal não há a pretensão de esgotar a discussão sobre a implementação de boas práticas administrativas na gestão de recursos materiais e patrimoniais. Enquadra-se como um estudo de caso de natureza exploratória, com abordagem qualitativa. A técnica principal de coleta de dados foi a entrevista em profundidade, conduzida a partir de um roteiro não estruturado, junto aos gestores diretos e indiretos dos cemitérios, totalizando três entrevistados, de setores distintos. $\mathrm{O}$ intuito principal do modelo concerne na identificação das necessidades relacionadas a real demanda dos empreendimentos. Além disso, a abordagem proposta procura o alinhamento dos processos genéricos relacionados aos cemitérios e a prefeitura municipal de Rondonópolis. Os resultados mostram que é preciso uma administração eficaz dos sistemas, nesse caso específico à Gestão de Materiais, com a finalidade de torná-lo adequado ao princípio da eficiência e de economicidade e adaptado às novas configurações econômicas.

Palavra-chave: Administração Pública; Cemitérios de Rondonópolis; Gestão de Materiais.

\begin{abstract}
This study proposes a management model of materials based on planning for public administration of the cemeteries of Rondonópolis-MT and, therefore, should not be interpreted as prescriptive content, since it is not a manual that congregates instructions, but in a model proposal and therefore there is no pretension to exhaust the discussion about the implementation of good administrative practices in the management of material and patrimonial resources. It is a case study of an exploratory nature, with a qualitative approach. The main technique of data collection was the in-depth interview, conducted from an unstructured road map, with the direct
\end{abstract}


and indirect managers of the cemeteries, totaling three interviewees, from different sectors. The main purpose of the model is to identify the needs related to the real demand of the enterprises. In addition, the proposed approach seeks the alignment of generic processes related to the cemeteries and the municipal government of Rondonópolis. The results show that an efficient administration of the systems, in this specific case to Materials Management, is necessary in order to make it appropriate to the principle of efficiency and economy and adapted to the new economic configurations.

Keywords: Public Administration; Cemeteries of Rondonópolis; Materials Management.

\section{CONSIDERAÇÕES INICIAIS}

Compreende-se que o enfoque de uma empresa é maximizar o retorno sobre o capital investido e é inegável que em qualquer tipo de organização há a necessidade de administrar os recursos escassos. Desta forma, a gestão acurada repousa na determinação das alternativas para acesso a recursos, bem como para a eliminação de desperdícios em sua utilização, consubstanciando modos de angariar vantagem competitiva - na esfera privada - ou expressões do binômio eficiência e economicidade - na esfera pública (FENILI, 2015).

$\mathrm{Na}$ Administração Pública tal perspectiva tem suas atividades-meio enfocadas na gestão de estoques, compras, guarda e acondicionamento de bens, distribuição e administração patrimonial. Tal fato se aplica a qualquer empreendimento sobre a gestão da administração pública, até mesmo aos cemitérios, cuja finalidade é o sepultamento dos cadáveres ou restos mortais (DERBLY, 2017), mas que devido o seu caráter mórbido acaba sendo um tema pouco trabalhado e discutido pela academia.

Destaca-se que os cemitérios são de interesse social e por isso a sua gestão deve ser pautada nos mesmos princípios que regem a administração pública. Mediante essa realidade, levantar informações, especificamente, sobre a atual gestão de materiais sobre esse segmento na cidade de Rondonópolis, torna-se um assunto de interesse social, uma vez que pretendeu-se identificar as principais dificuldades, barreiras e empecilhos a efetividade da gestão de materiais.

É nesse contexto que o presente artigo se insere, visando prover um modelo sobre Gestão de Materiais pautada em um Planejamento Financeiro para os cemitérios, à luz das peculiaridades do setor público municipal de Rondonópolis-MT, colocando-se à disposição o ferramental necessário para que a máxima utilização dos recursos - corolário imediato do princípio da economicidade - seja desdobrada de maneira satisfatória em suas diversas subatividades.

É evidente que com a melhoria na gestão de materiais não resolveria o problema de gestão dos cemitérios, uma vez que é necessária uma análise ampla de todos os processos inerentes a atividade principal. Contudo esse trabalho apenas propõe um modelo que poderia ser aplicado às demais esferas administrativas.

Ressalta-se, ainda em caráter introdutório, que este trabalho não deve ser interpretado como conteúdo prescritivo, pois não se trata de um manual que congrega instruções, mas sim em uma proposta de modelo de Gestão de Materiais. Da mesma forma, não há a pretensão de esgotar a discussão sobre a implementação de boas práticas administrativas na gestão de recursos materiais e patrimoniais.

Em relação à estrutura da pesquisa, em primeira instância, o referencial teórico concernente ao tema; em seguida, é apresentada a descrição dos procedimentos metodológicos; 
num terceiro momento, é apresentada a análise das entrevistas de forma sucinta e seus respectivos resultados e, por conseguinte, tendo como base os resultados coligidos, a proposição de um novo modelo. Por fim, as Considerações finais, especialmente quanto às contribuições da pesquisa, encerram o trabalho.

\section{REFERENCIAL TEÓRICO}

\section{GESTÃO PÚBLICA}

Nas duas últimas décadas, o governo brasileiro percebeu a necessidade de alterar os modelos de Gestão Pública, de Gestão Burocrática para Gerencial. A evolução da Gestão Pública Burocrática para Gerencial indica uma tendência de modernização do serviço público na qual se insere a adoção de métodos de Gestão de Materiais (SILVA et al, 2016, p. 2).

O conceito de administração pública na verdade é que "Não existem países desenvolvidos e países subdesenvolvidos, e sim países que sabem administrar a tecnologia e os recursos disponíveis e potenciais, e países que ainda não o sabem" (DRUCKER, 2001, p. 65), sendo assim temos a Administração pública que consiste em "[...] corresponde à face do Estado (o Estado-Administração) que atua no desempenho da função administrativa, objetivando atender concretamente os interesses coletivos" (CUNHA JUNIOR, 2015, p.26). Assim, compreende que é

O processo estruturado de planejamento, organização, orientação, execução, avaliação e aprimoramento das atividades da instituição pública no direcionamento para atender as necessidades e expectativas dos cidadãos da comunidade, visando ao bem comum (OLIVEIRA, 2014, p. 4).

A administração pública deve atender as necessidades e expectativas da população; e para conseguir fazer isso, é necessário que se conheça essas necessidades e expectativas; e para conhecê-las, é necessário que a população tenha efetiva participação na administração pública; e, para que a população queira participar, é necessário que ela acredite na administração pública (OLIVEIRA, 2014).

O município é compreendido como o nível de governo mais próximo do cidadão em geral, onde os efeitos da gestão pública afetam diretamente a vida das pessoas. Em uma grande parte das cidades, a administração municipal é a organização local mais importante: a que mais efetua relacionamentos e transações com a população, a que gera maior número de empregos, a que mais afeta a rotina e o bem-estar das pessoas que lá vivem (ANDRIOLO; VIEIRA; MEDEIROS, 2001).

Compreendido os conceitos preliminares voltados a gestão pública a seguir é apresentada as legislações pertinentes a Gestão de Materiais à esfera pública.

\section{GESTÃO DE MATERIAIS NA ESFERA PÚBLICA}

O Decreto $\mathrm{n}^{\circ}$ 99.658/19902, no artigo $3^{\circ}$, lista alguns dos exemplos dos recursos materiais em órgãos públicos, considerando que material é a denominação genérica de equipamentos, componentes, acessórios, veículos em geral, matérias-primas e outros produtos empregados ou passiveis de emprego nas atividades dos órgãos e entidades públicas federais, independentemente de qualquer fator (FENILI, 2015). 
A Constituição Federal de 1988, no caput de seu art. 37, torna explícito alguns princípios que devem nortear o funcionamento da administração pública brasileira obrigatória para todos os Poderes (Executivo, Legislativo e Judiciário), aplicável à administração pública direta e indireta, sendo válidos em todas as esferas de governo (União, Estados, Distrito Federal e Municípios).

Art. 37. A administração pública direta e indireta de qualquer dos Poderes da União, dos Estados, do Distrito Federal e dos Municípios obedecerá aos princípios de legalidade, impessoalidade, moralidade, publicidade e eficiência [...] (Brasil, 1988 apud FENILI, 2015, p. 16, grifo do autor).

Mediante isso, na busca pela melhor utilização possível dos recursos públicos, tem-se os princípios da eficiência que regem a administração pública.

[...] o princípio da eficiência é aquele que impõe à administração pública direta e indireta e a seus agentes a persecução do bem comum, por meio do exercício de suas competências de forma imparcial, neutra, transparente, participativa, eficaz, sem burocracia e sempre em busca da qualidade, primando pela adoção dos critérios legais e morais necessários para a melhor utilização possível dos recursos públicos, de maneira a evitar-se desperdícios e garantir-se uma maior rentabilidade social. (MORAES, 2010, p. 333).

Nota-se que esse princípio aproximasse da concepção de economicidade, uma vez que para a consecução do melhor custo versus benefício nas atividades da administração pública, de forma a evitar o desperdício do dinheiro público. É justamente por tal razão contextual que a gestão de materiais na administração pública se faz necessária, sendo dever do agente empregá-los da melhor forma. (FENILI, 2015).

O objetivo principal da gestão de matérias é a maximização dos recursos dentro da organização de modo que consiga diminuir os desperdícios. Considerando a sucessão de atividades que tem na gestão de matérias, o objetivo pode se desmembrar e tornar-se em secundários, conforme relacionados: para suprir as organizações dos materiais que sejam necessários para o desempenho, no momento certo, com qualidade, com preços econômicos, armazenamentos de modo apropriados, logo em seguida distribui-los aos setores, assim conseguindo evitar estoque desnecessários e manter as rotinas de controle efetivas (FENILI, 2015).

A gestão de matérias é feita da seguinte forma (FENILI, 2015):

I) Gestão dos centros de distribuição e recebimentos, armazenagem, distribuição, movimentação de materiais;

II) Gestão de estoques de forma a analisar os custos de estoque, é feita a previsão de consumo, operacionalização dos sistemas de reposição de estoque, inventários de estoque, faz-se a apuração dos indicadores;

III) Gestão de compras para a identificação de fornecedores, além da pesquisa dos preços, também faz negociação com o mercado, licitações, compras diretas quando não precisa fazer o processo de licitação, acompanhamento do pedido, liquidação; e

IV) Gestão de recursos patrimoniais, tombamento, alienação, guarda e conservação dos materiais. 
Por fim, entende-se que o objetivo da administração de recursos materiais é uma sequência de operações tendo início na identificação dos fornecedores, na compra de um bem ou serviço, no ato de seu recebimento, transporte interno e armazenagem, no transporte durante todo o processo produtivo, na armazenagem como produto acabado, até então com destino a sua distribuição final. A administração de materiais vai muito além do que um simples controle de estoque, engloba um vasto campo de relações essas que são interdependentes e que precisa ser bem orientado para evitar desperdícios (HENRIQUES, 2014).

\section{CEMITÉRIOS}

Os cemitérios constituem atualmente em uma necessidade social no Brasil. Tais empreendimentos existem desde a Idade Média, sendo que os cadáveres eram enterrados no interior das igrejas e nas áreas vizinhas, mas por razões higiênicas e de saúde pública passouse a enterrá-los em regiões ditas como apropriadas, a periferia das áreas urbanas (SILVA; SUGUIO; PACHECO, 2008; SILVA et al., 2016). De forma mais formalizada

Os cemitérios são retratados como grandes terrenos contornados e ordenados segundo um determinado processo paisagísticos. A resolução do CONAMA $n^{\circ} 335$ de 2003 instaurou regras para organizar a implantação de cemitérios no Brasil e classificou os cemitérios em quatro tipos sendo eles: horizontais, verticais, parques ou jardins e os de animais (BRASIL, 2003 apud SILVA et al., 2016, p. 4).

Quanto à natureza jurídica dos cemitérios é difícil conceituar, pois na própria doutrina não há um consenso, pois alguns entendem tratar-se de uma atividade de domínio privado, enquanto outros compreendem como empreendimento de domínio público devido à natureza jurídica do direito de sepultura (DERBLY, 2017). No entanto, o conceito jurídico de cemitério, compreende como "[...] bens imóveis, públicos ou privados, de uso especial, destinados ao sepultamento dos cadáveres ou restos mortais, sob o poder de polícia mortuária do município" (DERBLY, 2017).

Conforme o contexto apresentado anteriormente é possível compreender o porquê de por vezes os envolvidos na relação cemitérios e a gestão municipal não entenderem a quem cabe certas responsabilidades e atividades. Por fim, a seguir são apresentados os procedimentos metodológicos que orientaram a construção desse artigo.

\section{PROCEDIMENTOS METODOLÓGICOS}

Essa pesquisa se faz necessária uma vez que pretende propor um modelo que aprimore a forma como é feita a Gestão de Materiais em seus aspectos teórico-metodológicos com a finalidade de torná-la mais eficaz e adaptável às novas configurações e organizações na relação cemitérios e a gestão municipal. Com isso, o tipo de pesquisa fundamentou-se em um estudo de caso, caracterizando-se como um estudo multicascos uma vez que envolve duas unidades de análise (GODOY, 2005; YIN, 2005), que são os dois cemitérios públicos.

Com o intuito de alcançar o objetivo geral proposto o presente artigo implicou em uma "[...] construção conceitual e teórica cuidadosa, além da observância a ditames metodológicos" (MATTOS, 2008; VASCONCELOS, 2009 apud MASCARENHAS; BARBOSA, 2013, p. 37). A questão de pesquisa é tratada de forma dedutiva (SELLTIZ et al, 2007) e até mesmo de forma indutiva, após a análise exploratória dos dados. 
A metodologia de estudo enquadra-se por uma pesquisa qualitativa e exploratória, sendo essa metodologia mais adequada para atender a proposta central. Compreende-se que "a investigação exploratória é realizada em área que há pouco conhecimento acumulado e sistematizado" (VERGARA 2013, p. 41).

Para tanto propõem-se a construção de um modelo engendrado a partir de embasamento teórico já existente. O contexto da pesquisa limita-se aos cemitérios públicos do município de Rondonópolis, Mato Grosso. Tais empreendimentos foram selecionadas em uma amostra intencional, de forma a identificar as principais dificuldades, barreiras e empecilhos a efetividade da gestão de materiais a esses empreendimentos.

A técnica principal de coleta de dados foi a entrevista em profundidade, conduzida a partir de um roteiro semiestruturado por categorias levantadas a partir do referencial teórico, sendo as entrevistas realizadas junto aos gestores, diretos e indiretos, dos cemitérios, em um total de três entrevistados, que participam do processo de gestão de materiais, porém em etapas e setores distintos.

Ainda as visitas aos empreendimentos permitiram a prática de observação não participante, na perspectiva do pesquisador/observador (GODOY, 2005), pautando-se das mesmas categorias utilizadas no roteiro de entrevistas. Com intuito de documentar as entrevistas foram gravadas e transcritas para que as falas dos entrevistados fossem analisadas, a partir da técnica de análise de conteúdo (BARDIN, 1979; VERGARA, 2013).

O procedimento analítico iniciou-se com a organização e sistematização das entrevistas em categorias, sendo as respostas dos gestores diretos dos cemitérios compiladas em uma única categoria. Para tanto se buscou organizar os relatos, identificando-se passagens, em um processo de análise temática conforme categoria (YIN, 2005): o desmembramento dos temas foi feito conforme temática principal e das práticas de gestão de materiais. Em seguida procedeu-se a uma nova leitura desses segmentos de entrevistas, agrupando-os segundo os valores neles expressos, em um processo de interpretação.

Por fim, após o levantamento da sobre a gestão de materiais nesses empreendimentos, constatou-se ser evidente a carência e insuficiência na atual administração, tornando-se um empecilho a premissa de economicidade, contudo isso será apresentado com mais detalhes e profundidade no próximo tópico.

\section{COMPARTILHANDO AS DESCOBERTAS DA PESQUISA}

\section{CARACTERIZAÇÃO DO EMPREENDIMENTO}

A seguir é apresentada a região em que se encontram os cemitérios públicos e o Órgão responsável pela Gestão municipal. 
Figura 1: Localização geográfica dos empreendimentos analisados

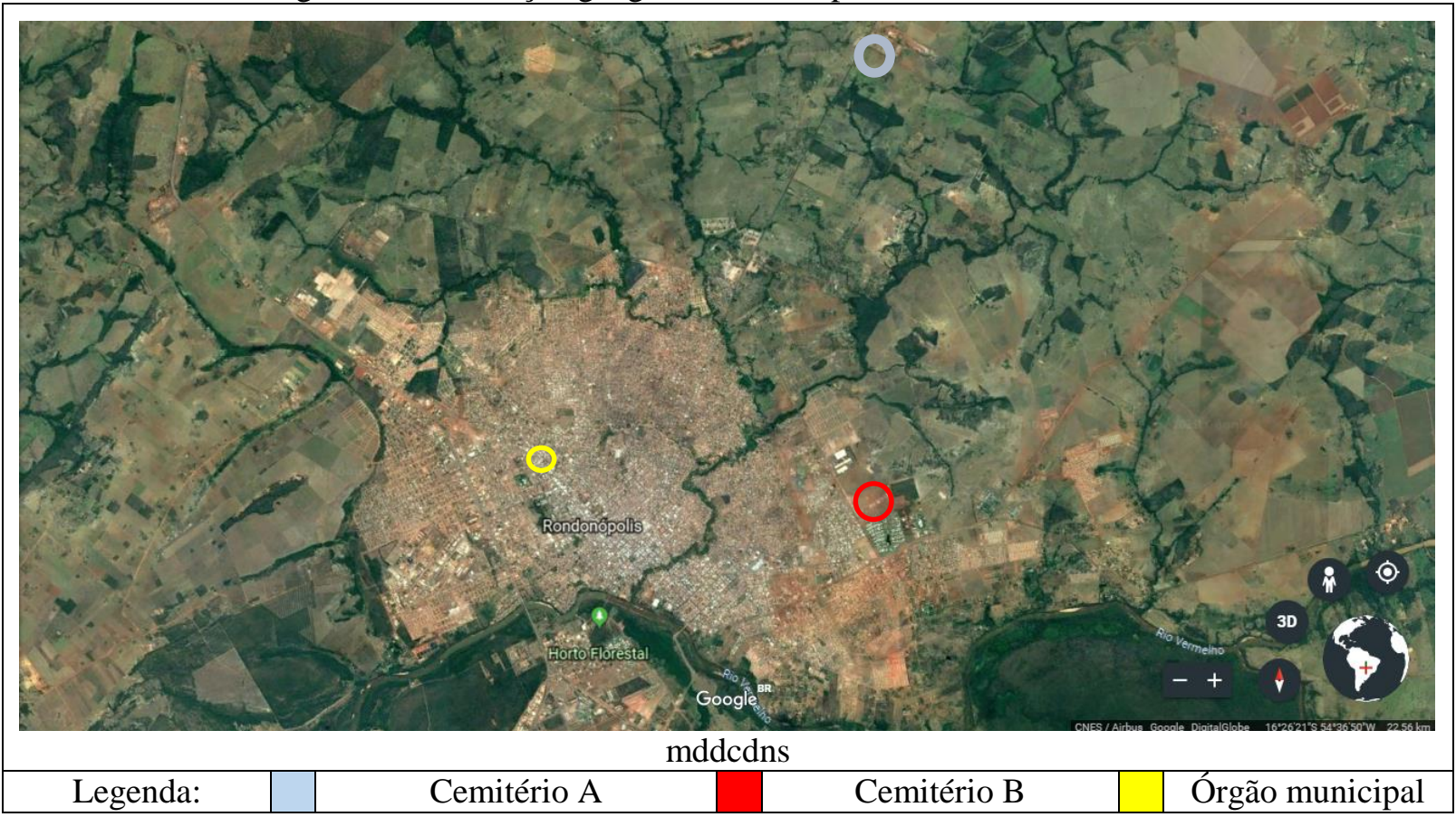

Fonte: Google Earth com adaptações (2017)

Ambos os cemitérios apresentados existem desde antes o início dos bairros ali existentes e inicialmente eram administrados pela comunidade local sem qualquer orientação específica, “[...] somente após a Portaria $\mathrm{N}^{\mathrm{o}}$ 001, de 26 de março de 2007 e o Decreto no 4.597 de 17 de maio de 2007 que houve a determinação de que a gestão do empreendimento seria de responsabilidade da prefeitura" (SILVA et al., 2016, p. 6).

Conforme Figura 1 é possível verificar que os cemitérios e o órgão responsável pela gestão municipal situam-se em áreas diferentes. Ao analisar o aspecto distância quando comparados à prefeitura o cemitério A fica a $28,6 \mathrm{~km}$ enquanto que o cemitério $\mathrm{B}$ fica $2,3 \mathrm{Km}$, tal distância acaba por ser um obstáculo a gestão direta. A distância torna difícil o abastecimento e acompanhamento por parte do órgão municipal competente.

Mediante a esses obstáculos e de forma a facilitar a gestão desses empreendimentos a Prefeitura municipal de Rondonópolis nomeou um representante legal para gerir as demandas e questões internas, ficando ao encargo da prefeitura apenas as auditórias para avaliação dos procedimentos. Para melhor compreensão da estrutura hierárquica dos cemitérios é apresentado a seguir o organograma.

Figura 2: Estrutura Hierárquica

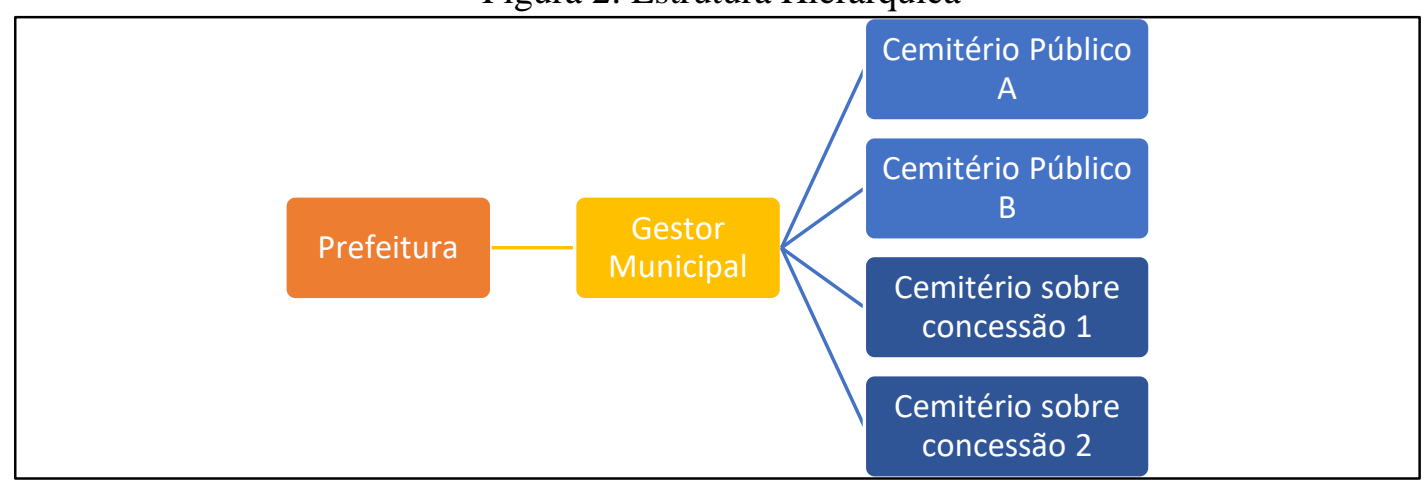

Fonte: Elaborado pelos autores (2017) 
É importante, relatar que esses são cemitérios que estão em processo de regulamentação para consequente regularização e por essa razão, muitos processos administrativos encontramse em defasagem, conforme informado em entrevistas.

Ainda sobre os processos relativos aos cemitérios há um projeto em que envolverá a procuradoria, secretaria de administração e de meio ambiente, juntamente com câmara de vereadores para elaboração do Planejamento para Ampliação para os serviços cemiteriais com as devidas restrições ambientais que limitam a sua ampliação.

Após as devidas apresentações das características da amostra em estudo é apresentada a seguir as entrevistas.

\section{ANÁLISE DAS ENTREVISTAS}

A seguir é apresentada a categorização das informações relevantes obtidas por meio das entrevistas realizadas com um representante da prefeitura e os dois funcionários responsáveis pelos cemitérios.

Quadro 1: Síntese das entrevistas

\begin{tabular}{|c|c|c|c|}
\hline \multicolumn{2}{|l|}{ Categoria } & Prefeitura & $\begin{array}{l}\text { Compilação das entrevistas dos } \\
\text { Cemitérios }\end{array}$ \\
\hline \multirow[t]{2}{*}{$\begin{array}{l}\text { Gestão de } \\
\text { Materiais }\end{array}$} & Demanda & $\begin{array}{l}\text { Levantamento de todo material que } \\
\text { é utilizado no cemitério (luva, } \\
\text { cimento, tijolo) depois é licitado, } \\
\text { sendo que a guarda fica no } \\
\text { almoxarifado da prefeitura ou nas } \\
\text { lojas. É disponibilizado o material } \\
\text { conforme necessidade e só pode } \\
\text { ser retirado pelo gerente dos } \\
\text { cemitérios. }\end{array}$ & $\begin{array}{l}\text { Realizado através do montante da } \\
\text { taxa de anuidade é realizada a } \\
\text { compra do material, sendo } \\
\text { realizado o acerto ao final do mês } \\
\text { junto a prefeitura. }\end{array}$ \\
\hline & $\begin{array}{ll}\text { Lista de } \\
\text { Materiais }\end{array}$ & $\begin{array}{l}\text { Determinado pelos responsáveis } \\
\text { pelos cemitérios }\end{array}$ & $\begin{array}{l}\text { Material de Consumo é o saco de } \\
\text { exumação, material para limpeza, } \\
\text { papel higiênico, cimentos, tijolo, } \\
\text { pá, carriola e colher de pedreiro. }\end{array}$ \\
\hline \multirow{2}{*}{$\begin{array}{l}\text { Gestão de } \\
\text { Estoque }\end{array}$} & $\begin{array}{l}\text { Controle de } \\
\text { saída }\end{array}$ & $\begin{array}{l}\text { Há um bloco de controle para } \\
\text { solicitação que deve ser assinado } \\
\text { para liberação no almoxarifado }\end{array}$ & $\begin{array}{l}\text { O controle é realizado por meio } \\
\text { da observação direta do } \\
\text { almoxarifado do cemitério, com } \\
\text { um bloco anotando tudo que } \\
\text { precisa. }\end{array}$ \\
\hline & Organização & $\begin{array}{l}\text { Determinado pelo departamento } \\
\text { responsável pelo almoxarifado }\end{array}$ & $\begin{array}{l}\text { Organizado conforme utilização e } \\
\text { peculiaridades do material. } \\
\text { *Utiliza-se do método PEPS, } \\
\text { primeiro a entrar, primeiro a sair. }\end{array}$ \\
\hline \multirow[t]{2}{*}{$\begin{array}{l}\text { Gestão de } \\
\text { Compras }\end{array}$} & Compras & $\begin{array}{l}\text { Pega de dois a três orçamentos para } \\
\text { avaliar o menor custo e marca }\end{array}$ & $\begin{array}{l}\text { Caso não tenha o material na } \\
\text { prefeitura é realizada a compra } \\
\text { com autorização da prefeitura no } \\
\text { mercado credenciado aonde tem } \\
\text { nota fiscal }\end{array}$ \\
\hline & Fornecedores & $\begin{array}{l}\text { Conforme licitação, } r \text { sendo } \\
\text { realizado por outro setor e } \\
\text { seleciona pelo menor preço. }\end{array}$ & \\
\hline
\end{tabular}




\begin{tabular}{|c|c|c|c|}
\hline \multirow{2}{*}{ Financeiro } & Controle & $\begin{array}{l}\text { Prestam contas mensalmente por } \\
\text { meio das notas fiscais o que sobra } \\
\text { deposita em uma conta. }\end{array}$ & $\begin{array}{l}\text { Realizado por meio dos blocos de } \\
\text { recibos por onde é possível } \\
\text { mensurar a receita das taxas de } \\
\text { sepultamento e anuidade. }\end{array}$ \\
\hline & $\begin{array}{l}\text { Planejamento } \\
\text { de gasto anual }\end{array}$ & $\begin{array}{l}\text { Incumbência do gestor do núcleo e } \\
\text { ainda vai ser implantado, não } \\
\text { existe um valor ao certo. }\end{array}$ & \\
\hline \multirow[b]{2}{*}{$\begin{array}{l}\text { Sugestões } \\
\text { à pesquisa }\end{array}$} & Dificuldades & $\begin{array}{l}\text { Processo de regulamentação sem } \\
\text { ele é impossível avançar em outras } \\
\text { áreas para a devida gestão }\end{array}$ & $\begin{array}{l}\text { Não há mais espaço para } \\
\text { sepultamento. }\end{array}$ \\
\hline & Sugestões & $\begin{array}{l}\text { Tornar uma autarquia ou até } \\
\text { mesmo terceirizar o serviço }\end{array}$ & $\begin{array}{l}\text { Ampliar área para sepultamento e } \\
\text { a contratação de mais } \\
\text { funcionários para auxiliar nas } \\
\text { demais atividades, nos cemitérios } \\
\text { público A e B. }\end{array}$ \\
\hline
\end{tabular}

Fonte: Elaborado pelos autores (2017)

A partir da entrevista sintetizada no Quadro 1 verifica-se que não há uma efetiva Gestão de Materiais, sendo as atividades desenvolvidas de forma momentânea sem um olhar mais administrativo e estratégico aos processos. Quanto ao controle financeiro é evidente que há uma arcaica prestação de contas mensal, contudo não há um planejamento periódico do planejamento anual de gastos.

Compreende-se que mediante o processo realizado atualmente, é difícil a maximização do uso dos recursos materiais na organização pública, conforme rege o princípio de economicidade. Assim, com base nesses achados e na revisão da literatura a seguir é apresentada uma proposição de modelo para a gestão de materiais dos cemitérios.

\section{PROPOSIÇÃO DE UM MODELO DE GESTÃO DE MATERIAIS}

A revisão de literatura apresentada e os resultados identificados mostram que é preciso uma administração eficaz dos sistemas, nesse caso específico à Gestão de Materiais, com a finalidade de torná-la adequados ao princípio da eficiência e de economicidade e ainda adaptado às novas configurações econômicas.

O modelo de Gestão de Materiais apresentado a seguir propõe uma restruturação das atividades, que envolverá a definição de parâmetros compatíveis com os respectivos níveis de tarefas, análise prospectiva de necessidades e a hierarquização das necessidades.

$\mathrm{O}$ intuito principal do modelo concerne na identificação das necessidades relacionadas a real demanda dos empreendimentos. Além disso, a abordagem proposta procura o alinhamento dos processos genérico relacionado aos cemitérios e a prefeitura municipal de Rondonópolis, propondo-se uma metodologia passível de replicação para demais empreendimentos públicos. No próximo tópico é apresentada a forma como seriam as etapas do modelo proposto. 
Figura 3: Modelo Conceitual para Gestão de Materiais

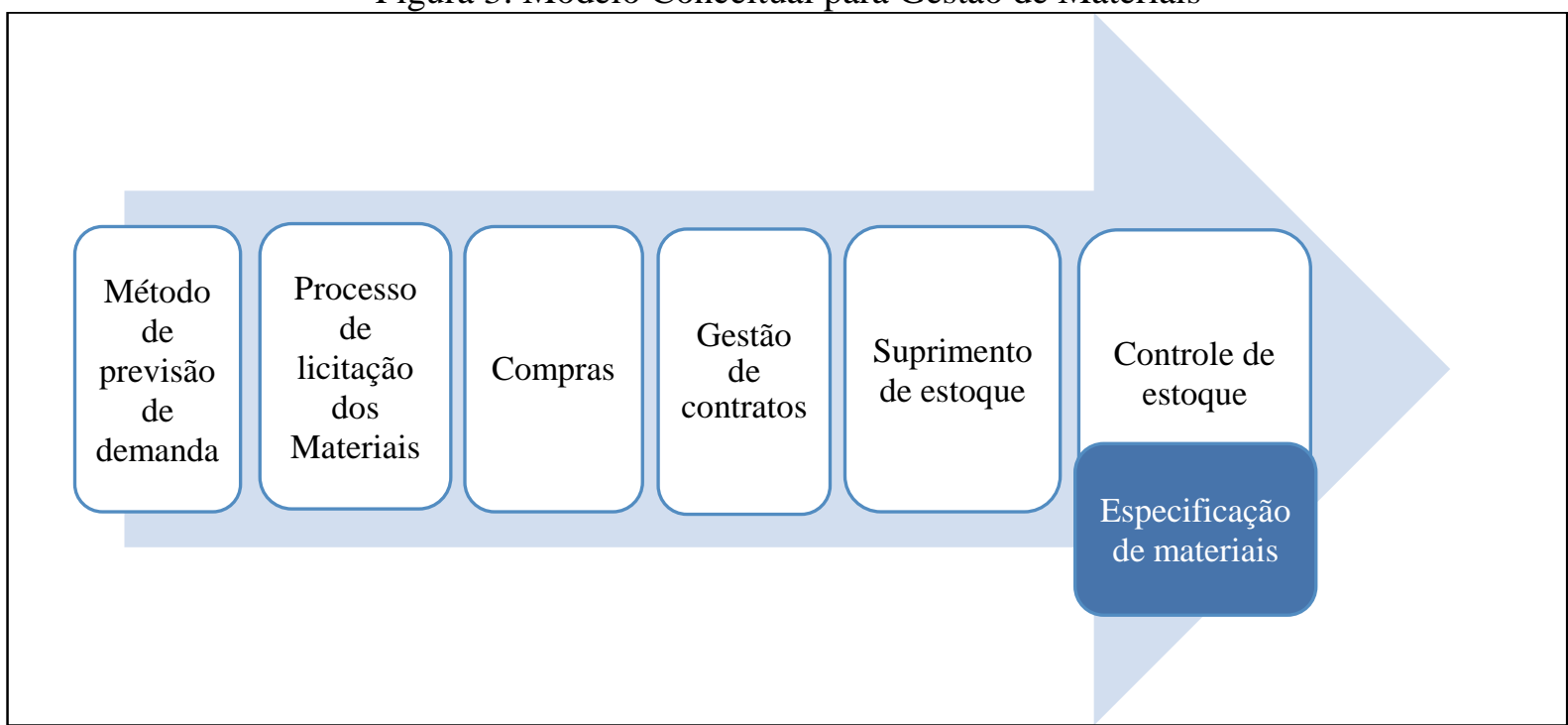

Fonte: Elaborado pelos autores (2017)

\section{PREVISÃO DA DEMANDA}

Ao se falar no controle de estoque é imprescindível a realização da previsão de demanda (consumo) de determinado material buscando que seja o mais próximo da realidade, no entanto, cabe considerar que essa não é uma metodologia exata (DIAS, 2012).

Ao realizar o planejamento da previsão da demanda é necessário considerar: potencial de mercado, tamanho de mercado, participação da organização do mercado e crescimento do mercado (KOTLER, 1990).

Quanto às informações utilizadas na determinação da demanda, essas podem considerar os dados históricos ou a manipulação de alguma forma ou por meio de técnicas estatísticas. No caso dos cemitérios é pertinente considerar o Método da média móvel que adota a média aritmética simples dos consumos dos períodos posteriores para estimativa de consumo futuro. Essa técnica enquadra-se ao contexto dos cemitérios uma vez que estes possuem uma evolução de consumo constante, ou seja, demanda "estável" não havendo variações significativas (FENILI, 2015).

A previsão pode ser calculada aplicando-se a seguinte fórmula:

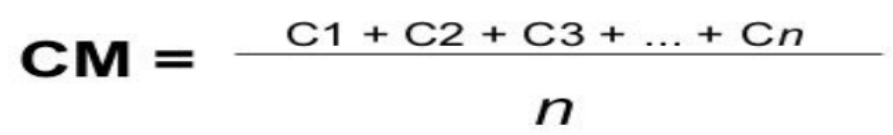

Onde:

CM: Consumo médio

C: Consumo nos períodos anteriores

N: número de períodos

Tal modelo já é preconizado no manual de Gestão de Materiais da Câmara dos Deputados "para aquele órgão, a previsão para períodos futuros a média do consumo mensal de um período compreendido até os últimos cinco anos" (FENILI, 2015, p. 47). 


\section{COMPRAS E PROCESSO DE SOLICITAÇÃO DE MATERIAIS}

Ao realizar o processo de compra para um órgão público é necessário conciliar a prática de um preço econômico com a aquisição de um bem com qualidade. Entretanto, aferir “[...] qualidade no produto adquirido é bem mais complicada quando a compra se dá por licitação, na qual a indicação de marca não é a regra, mas sim restrita a casos específicos" (FENILI, 2015, p. 85). O processo de compras inicia-se sempre com uma necessidade levantada por meio de uma solicitação, seguida de uma pesquisa de preço de mercado, análise e lançamento do preço, determinada por uma autorização e posterior contratação ou realização de uma licitação.

A Gestão de Compras é necessário considerar três atributos básicos: preco econômico, qualidade e celeridade. Compreendido os atributos é necessário especificar o processo de compras do setor público, conforme demonstrado na Figura 4.

Figura 4: Processo de compras para Administração pública.

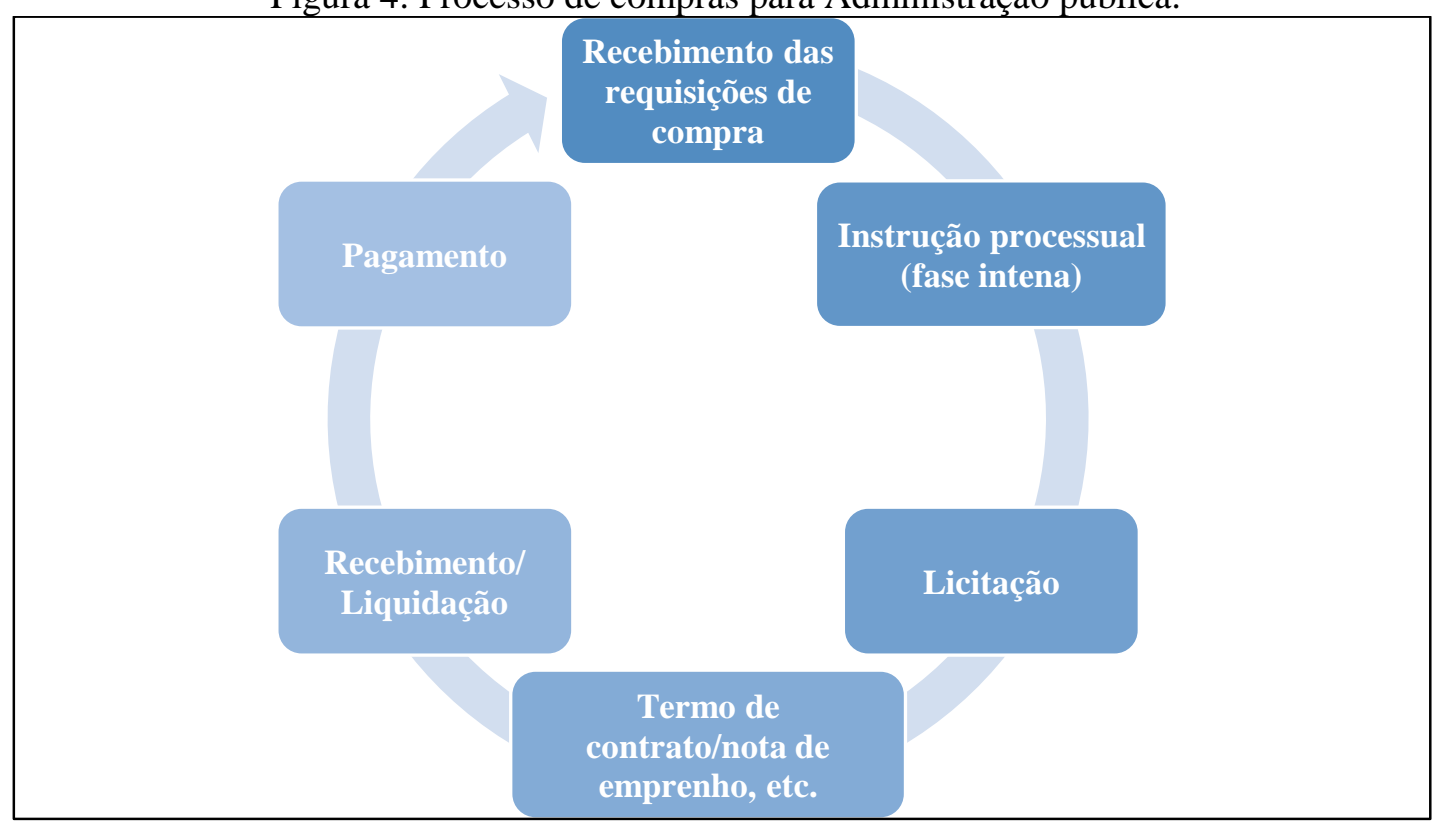

Fonte: FENILI (2015, p. 89).

É evidente que essa é uma sugestão é que devido a limitação das informações pode não considerar todos os aspectos envolvidos no processo de compras realizado pela Administração pública do Município de Rondonópolis - MT.

\section{GESTÃO DE CONTRATOS}

O contrato da Administração pública representa formalmente em um documento as obrigações entre contratante e contratado de forma reciproca, ou seja, une o que está determinado em edital à proposta vencedora para simplificar o controle e a organização, entretanto, compreende-se também que o contrato pode ser formalizado no decorrer da própria licitação, e não necessariamente depois dela (PARÍSIO, 2014). A Gestão de Contratos Administrativos é considerada como atividade complexa, uma vez que operacionalizar a aquisição é mais simples quando comparado com as etapas burocráticas que antecedem ou lhe sucedem (GOMES, 2016). 
O vigente regime licitatório e os consequentes contratos administrativos estão submissos às regras especiais de norma (BRASIL, 1993). No caso do fornecimento de materiais necessários as atividades dos cemitérios a espécie de contrato é o de fornecimento de Bens de Consumo e permanente. No entanto é de conhecimento que a administração pública independente da esfera realiza diversas licitações e por tal se faz necessária a Gestão dos Contratos no intuito de gerenciar, acompanhar e fiscalizar a execução dos ajustes, "desde a concepção do edital da licitação até a entrega e o recebimento do objeto contratado" (RIBEIRO, 2010, p. 10).

Quanto à fiscalização, a Lei n ${ }^{\circ}$.666/1993 dispõem para os Poderes da União, Estados, Distrito Federal e Municípios no art. 67 que:

[...] a execução do contrato deverá ser acompanhada e fiscalizada por um representante da Administração especialmente designado, permitida a contratação de terceiros para assisti-lo e subsidiá-lo de informações pertinentes a essa atribuição, sujeita à regra geral da prévia licitação. (BRASIL, 1993, p. s/n).

Ademais, o processo de fiscalização do contrato é uma valorosa ferramenta de defesa do interesse público, pois permite a efetividade da oferta de forma a garantir que seja realmente a mais vantajosa proposta contratada pela Administração pública, quer seja na prestação de serviços, no fornecimento de bens ou na utilização de imóveis.

\section{GESTÃO DE ESTOQUES}

Há diferenças na gestão de bens e serviços, uma vez que os serviços são intangíveis e envolvem um esforço ou desempenho e bens são tangíveis e por tal razão não tem como estocar os serviços, mas os insumos usados podem e devem ser armazenados (BERRY, 1980; LOVELOCK, 1981).

A gestão de estoque é a parte que se responsabiliza por adequar os níveis de estoques a necessidade e política de gestão de matérias de uma organização (PARÍSIO, 2014). Algumas empresas atualmente já operam sem estoques, mas devido as características peculiares dos serviços públicos, a burocracia envolvida e os extensos prazos aquisições de materiais, há a obrigatoriedades de uma manutenção com estoque mínimo ou de segurança que possa garantir o funcionamento adequado de um órgão (PARÍSIO, 2014).

No caso específico dos cemitérios conforme as peculiaridades e funções que desempenha enquadram-se como Estoque de antecipação uma vez que é criado para antecipar uma demanda futura.

Sugerimos um modelo que facilite o controle de entradas e saídas desses produtos, fazendo isso por um método de catalogação, especificação, normalização, padronização e grau de controle proporcional à importância dentro do grupo em relação a todos os materiais existentes dentro desse espaço (PARÍSIO, 2014), apresentados a seguir:

- Catalogação que deverá fazer uma listagem de tudo que existe dentro desse estoque sem nenhuma omissão;

- Normalização será a maneira pelo qual os materiais devem ser utilizados em suas devidas aplicações;

- Padronização destes produtos estabelecendo um padrão idêntico de peso, medidas e a dimensão dos mesmos para que exista uma variação;

- Grau de controle proporcional à importância do grupo estabelecendo a prioridade dos itens. 
A codificação vem da decorrência das etapas anteriores e é a apresentação de cada produto por meio de um código que contenha informações especificas e necessárias como números ou letras, então devido a necessidade do cemitério achamos devido utilizar um sistema alfabético que faz a codificação dos materiais através de um conjunto de letras e cada uma identificando características especificas (PARÍSIO, 2014).

O método de controle mais apropriado para os cemitérios é o sistema dos máximos e dos mínimos, que trabalha com quantidade fixas, uma vez que há dificuldade para se identificar a quantidade do consumo e a variação de tempo das requisições (PARÍSIO, 2014).

Para determinação do Estoque Mínimo e Máximo utilizam-se as fórmulas a seguir:

$$
\mathrm{E} \min =\mathrm{ER}+\mathrm{d}^{* \mathrm{t}} \quad \mathrm{E} \max : \mathrm{E} \min +\text { lote de compra }
$$

Sendo:

ER: estoque de reserva

d: consumo médio do material

t: tempo de espera, esse sendo em dias para reposição.

Relativo à avaliação do estoque, conforme Receita Federal (BRASIL, 1999), o mais adequado as peculiaridades dos cemitérios é o custo médio que, uma vez que permite aferir o preço médio entre todas as entradas e saídas de materiais e atua como um moderador de preços afim de minimizar eventuais variações (PARÍSIO, 2014).

Todo material que for armazenado gera um custo de estocagens, e este custo fica dependente de duas variáveis que são: a quantidade em estoque e por quanto tempo ela permanecera (PARÍSIO, 2014).

A que se encaixa devidamente para a Administração Pública dos cemitérios é o custo inversamente proporcionais que também é conhecido por custo de pedido $(\mathrm{CP})$, é o que decresce com o aumento da quantidade média em estoque, uma vez que ela assume que o preço por emissão do pedido seja fixo, isso sendo independentemente da quantidade que foi solicitada (PARÍSIO, 2014; FENILI, 2015), conforme Equação a seguir:

$$
\mathrm{CP}=\mathrm{CAP} / \mathrm{N}
$$

Sendo:

CP: custo de pedido

CAP: custo anual dos pedidos

N: número de pedidos no ano

\section{CONSIDERAÇÕES FINAIS}

A Gestão em si já é uma tarefa complexa e bem abrangente, mas quando limitamos a análise a gestão de materiais voltada a Administração Pública há um significativo desafio por causa das diversas particularidades e por conta dos inúmeros fatores que contribuem para o descontrole. O ideal é que houvesse uma "receita" para solucionar essa questão, entretanto, não é essa a realidade. Mediante esse aspecto o presente trabalho apresentou uma proposição de modelo para a Gestão de Materiais à Administração Pública, especificamente para os cemitérios.

Objetivo deste estudo foi propor um modelo de gestão de materiais pautadas em um planejamento para Administração pública dos cemitérios de Rondonópolis-MT, ressalta-se que 
esse trabalho não deve ser entendido como um conteúdo prescritivo e sim como proposta de modelo de gestão de materiais.

Conforme análise das entrevistas com os gestores pode se observa claramente que não há uma efetiva Gestão de Materiais, apesar de haver um alinhamento das visões das áreas envolvidas em relação ao atual processo, entretanto ainda há falhas na previsão de demanda e na gestão desses materiais, podendo se concluir que mediante os processos que estão sendo realizada a dificuldade em maximizar o uso dos recursos materiais dentro da organização pública.

Após analisar todo esse contexto e com toda revisão bibliográfica, foi apresentado uma proposta de um modelo de gestão de materiais. Quanto à parte relativa ao processo de "compras e processo de solicitação de materiais" esclarecemos que foi definido a partir de um Benchmarking com Sistema S por ter maior compatibilidade e afins com a organização em estudo.

Como contribuição temos uma proposta de modelo que pode ser aplicada a demais setores considerando as devidas adaptações. Ressaltamos que esse é um trabalho de caráter acadêmico e que por tal pode haver fatores que não foram considerados ao longo da pesquisa, representando como as limitações deste estudo. Destarte, sugerem-se às abordagens futuras uma pesquisa quantitativa e qualitativa, utilizando-se da metodologia proposta para verificação da efetividade do modelo para as necessidades de Gestão de Materiais para os cemitérios da Administração Pública e consequentes alteração ou sugestão de melhoria.

\section{REFERÊNCIAS}

ANDRIOLO, L. J.; VIEIRA, M. M. F.; MEDEIROS, J. J. Um modelo para análise de desempenho de organizações da administração pública municipal. Organizações \& Sociedade, v. $8, \quad$ n. 20, p. 1-13, Janeiro-Abril, 2001. Disponível em: <https://www.portalseer.ufba.br/index.php/revistaoes/article/view/10563>. Acesso em: 22 de jul. de 2017

BARDIN, L. Análise de conteúdo. Lisboa, Edições Setenta, 1979.

CUNHA JUNIOR, Dirley da. Curso de Direito Administrativo. 14. ed. Salvador: Juspodivm, 2015.

DERBLY, R. J. P. Natureza jurídica dos cemitérios. In: Âmbito Jurídico, Rio Grande, VI, n. 13, maio 2003. Disponível em: <http://www.ambitojuridico.com.br/site/index.php?n_link=revista_artigos_leitura\&artigo_id=3590>. Acesso em 09 set. 2017.

DIAS, M. A. P. Administração de Materiais: Princípios, conceitos e gestão. 6.ed. São Paulo: Atlas, 2011.

DRUCKER, P. F. A profissão de administrador. São Paulo: Pioneira Thomson Learning, 2001

FENILI, R. R. Gestão de Materiais, Brasília: ENAP, 2015. Disponível em: $<$ http://www.enap.gov.br/documents/52930/707328/Enap+Did\%C3\%A1ticos++Gest\%C3\%A3o+de+Materiais.pdf/76d26d48-37af-4b40-baf1-072a8c31236a>. Acesso em: 10 ago. 2017. 
GODOY, A.S. Estudo de caso qualitativo. In: GODOI, C.K.; BANDEIRA-DE-MELLO, R.; SILVA, A.B. da (Org.) Pesquisa qualitativa em estudos organizacionais: paradigmas, estratégias e métodos. São Paulo: Saraiva, 2006.

GOMES, A. R. G. A Gestão de Contratos na Administração Pública. Id on Line Revista de Psicologia, vol.10, n.29, Fev. 2016. p. 100-110. Acesso em: 10 ago. 2017.

HENRIQUES, José Thadeu Paulo. Administração de materiais. Disponivel em: http://www.aedmoodle.ufpa.br/pluginfile.php?file $=\% 2 \mathrm{~F} 160900 \% 2 \mathrm{Fmod}$ resource $\% 2 \mathrm{Fconten}$ t\%2F1\%2FADM\%20DE\%20MATERIAIS\%20-\%20\%20Livro\%20Castanhal.pdf

Acessado em: 09 mar. 2018

KOTLER, P. Marketing para Serviços Profissionais. São Paulo: Atlas, 1990.

LOVELOCK, C. H. Why Marketing Management Needs to be Different for Services. In: J. H. Donnelly and W. R. George (eds.), Marketing of Services. Chicago: American Marketing Association, 1981.

MORAES, A. Direito Constitucional. 26. ed. São Paulo: Atlas, 2010.

OLIVEIRA, D. de P. R. de. Administração Pública: Foco na eternização do modelo administrativo. São Paulo: Atlas, 2014.

SELLTIZ, C.; WRIGHTSMAN, L. S. III; COOK, S. W. Métodos de Pesquisa nas Relações Sociais. V. 1, delineamentos de pesquisa. São Paulo: EPU, 2007.

SILVA, F. C. da; SUGUIO, K.; PACHECO, A.. Avaliação ambiental preliminar do cemitério de Itaquera, segundo a resolução CONAMA 335/2003, município de São Paulo. Revista Geociências: UNG, v. 7, n. 1, p. $31-47,2008$.

SILVA, J. N. F.; SOARES, A. P.; SILVA, F. P. SANTOS, D. A. dos. Cemitérios de Rondonópolis: Um levantamento comparativo dos impactos socioambientais negativos. In: CONGRESSO DE ADMINISTRAÇÃO DO SUL DO MATO GROSSO, 4., 2016, Rondonópolis. Anais eletrônicos...Rondonópolis: UFMT, 2016. Disponível em: $<$ http://eventosacademicos.ufmt.br/index.php/CONASUM/index/schedConfs/current $>$. Acesso em: 10 jun. 2017.

VERGARA, S. C. Projetos e relatórios de pesquisa em administração. 14. Ed. São Paulo: Atlas, 2013.

YIN, R. K. Estudo de caso: planejamento e métodos. 3. ed. Porto Alegre: Bookman, 2005. 